appear that isolated cases have occurred in native-born South Africans who bave never left South Africa. These cases would, I think, repay very careful study on the line suggested by Dr. Cosnett. I consider it would also be useful if he were to investigate the incidence of retrotesbar neuritis in South Africa, which, I gather, is also extremely rare, and which is such a common early sign of disseminated sclerosis in any country.-I am, etc.,

A. M. G. Campbell.

Bristol, 8.

\section{Hand-operated Resuscitator}

SIR - I read with interest the article on a hand-operated Resuscitator by Dr. B. G. B. Lucas and his colleagues, (Journal. May 2, p. 1165). There is no doubt that there is a very real need for such an apparatus both for the reasons mentioned in the article and for industrial emergencies such as cases of electrocution and cyanide poisoning

I feel however that it is a pity that the facepiece, in every other way so well designed, could not have been made with a straight-forward British Standard push-on attachment as in the case of an anesthetic facepiece, in view of the fact that. like the Champetier de Ribes's bag, it is a rarely used piece of emergency equipment, and that the one time it is badly needed the facepiece will have perished and no readily available substitute will be to hand. This modification would also facilitate convertion to endotracheal intubation with manual control should the need arise.-I am, etc.,

British Military Hospital,

C. D. SAnders. Singapore.

\section{Diabetes in the Tropics}

SiR,- Your recent leading article on diabetes in the tropics (Journal, January 24, p. 219) and Dr. J. E. Cosnett's paper on the Natal Indian diabetics (p. 187) prompt us to record some of the developments in the treatment of diabetes at the King Edward Hospital, Durban, since Dr. Cosnett wrote his paper 18 months ago. During 1958 expansions in the hospital allowed the establishment of a diabetic clinic for Zula and Indian patients. Out of a total of over 650 patients at present attending we have extracted information on the first $\mathbf{4 0 5}$ (105 Zulus, $\mathbf{3 0 0}$ Indians). to restrict carbohydrate. All patients are lectured to in Zulu and English about dieting,urine testing, and syringe technique, and they are each given a rough diet sheet in keeping with the customs of both races. In a clinic in which no less that five types of diabetics are seen we have for obvious reasons avoided the use of the terms "Type 1 " and "Type 2." Table I shows the terms that we have used in our clinic. It is interesting to note that, unlike HughJones in Jamaica," we find the " $J$ " type of diabetic only in patients of Indian extraction and not in the African. In Dr. Cosnett's paper he quoted that $8 \%$ of all his Indian patients were of the " $J$ " type. In the present series, we have found only $2 \%$. The reason for this is twofold: firstly, we have a number of thin young Indian diabetics, who have been satisfactorily controlled on the oral antidiabetic drugs, and in whom we have never established insulin requirements because of the facility with which they have been controlled on oral therapy. Secondly, because we have applied most stringently our criteria (see Table I) in the diagnosis of the " $J$ " type-any patient who has shown acetone on even one occasion being excluded from this category.

In Table II we have set out the methods of treatment that have been employed in our first 405 cases-the criterion of control being that which would be regarded as "fair" in clinics in the U.S.A. or the U.K.

\begin{tabular}{|c|c|c|c|c|c|c|}
\hline \multirow{2}{*}{ Method of Treatment } & \multicolumn{3}{|c|}{ Indians (300) } & \multicolumn{3}{|c|}{ Zulus (105) } \\
\hline & Male & Female & Total & Male & Femate & Total \\
\hline $\begin{array}{l}\text { Diet only } 0-40 \text { units insulin } \\
\text { Diet and } 0-40 \text { daily } \\
\text { diet and over } \ddot{40} \text { anits insulin } \\
\text { daily } \\
\text { Diet and oral antidiabetic drug }\end{array}$ & $\begin{array}{r}15 \\
17 \\
9 \\
58\end{array}$ & $\begin{array}{r}31 \\
17 \\
19 \\
134\end{array}$ & $\begin{array}{r}46 \\
34 \\
28 \\
192\end{array}$ & $\begin{array}{r}2 \\
13 \\
8 \\
15\end{array}$ & $\begin{array}{l}5 \\
15 \\
14 \\
33\end{array}$ & $\begin{array}{r}7 \\
28 \\
22 \\
48\end{array}$ \\
\hline Totals & 99 & 201 & 300 & 38 & 67 & $\overline{105}$ \\
\hline $\begin{array}{l}\text { Saccessfully " converted" } \\
\text { from insulin to oral anti- } \\
\text { diabetic drug } \\
\text { dia }\end{array}$ & 25 & 40 & 65 & 12 & 15 & 27 \\
\hline
\end{tabular}

Dr. Cosnett noted in this paper that 11 out of a total of 207 patients were controlled on tolbutamide. Table II shows how much this has changed. Because of primitive syringe hygiene we have tried to wean as many patients as possible off insulin, and in our first $\mathbf{4 0 5}$ patients we have converted 92 from insulin to tolbutamide or another antidiabetic drug. These preparations have proved admirable in many patients, including many young people, of both races. Table II shows that many of our fat middle-aged diabetics are on the oral antidiabetic preparations (principally tolbutamide). We realize fully that this is bad diabetic practice, but, as the incomes of so many of our patients prevent their being able to afford other than a diet rich in carbohydrate, our aims

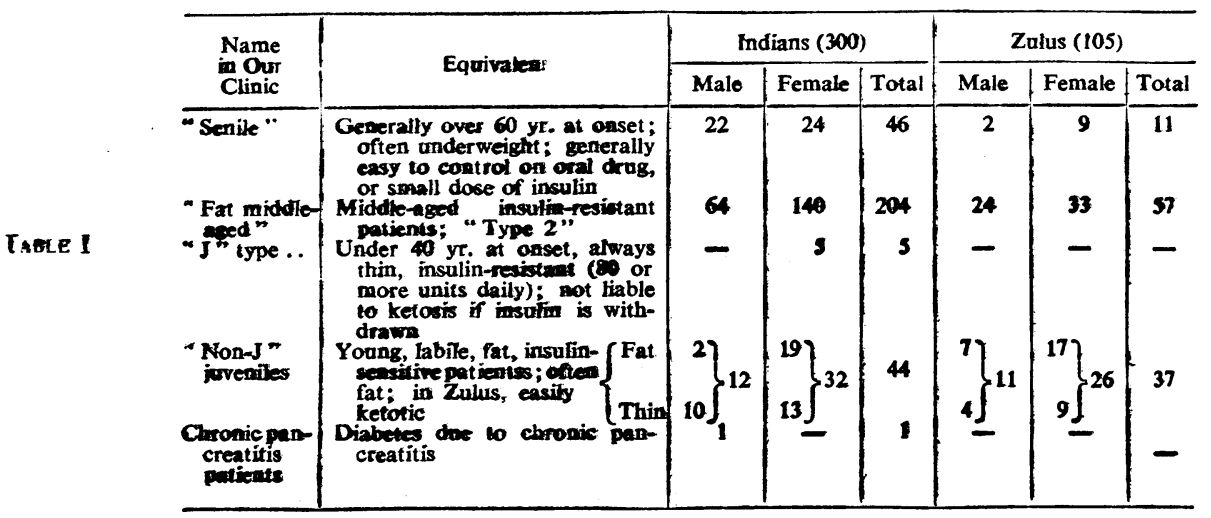

The chief problem with impecunious diabetics is that of trying to diet them satisfactorily. On account of poverty their diet is very hish in carbohydrate. We devoted our most earnest efforts to impressing upon our patients the need have been to try to relieve the troublesome symptoms of diabetes and to render the urine as free of sugar as possible. In this respect the oral antidiabetic drugs (tolbutamide. chlorpropamide, and metahexamide) have 
proved invaluable. In only four instances out of the 92 "conversions" from insulin to oral therapy had the patient to be put back on to insulin again. These conversions included not only fat middle-aged diabetics (who should not reaHy have been put on to insulin prior to their being referred to the clinic), but also several patients who had been ketotic; one Zulu woman, who had been admitted in diabetic coma, has now been satisfactorily controlled for over six months following an initial period on insulin. Hopes that the use of oral preparations would reduce the insulin requiremeats of the " $\mathrm{J}$ " type diabetics have not been realized, though, as stated above, certain of the milder thin young diabetics have been well controlled by these drugs; but we are not really in a position, yet, to say whether these are in fact " $J$ " types or not.

Diabetes is reputedly rare in the African. In a recently pubtished monograph on sickness in the African $^{2}$ a series of 17 is reported to have been collected in two years; of these 14 were males, and most were between 20 and 40 years of age ; treatment was regarded as being very unsatisfactory. In eight months we have been able to collect 135 Zulu diabetics (annual hospital turnover: 600,000 out-patients). Their study has proved most interesting and a detailed paper upon them is in the process of preparation.

We find there is a marked similarity between the European and Zulu diabetics; the Indians differ from both, in that they generally have a much milder form of disease, are more resistant to insulin, and it is in them only that the " $J$ " type of diabetic is found in Natal.

So far, we have counted ourselves successful in two ways: firstly in the regularity with which our patients attend, and secondly in that we have achieved weight losses in our Indian patients, which we would formerly have considered impossible; it is true to say that rigorous dietary control would reduce the number of patients in our clinic to one-third. We hope that, by trying to discipline our Indian patients, we may in time be able to avert the terrible diabetic complications seen in them, which have been summarized by Dr. Cosnett. On the whole our Zulu patients have been good and co-operative in their control, and they are infinitely more tractable patients than the Indians.-We are, etc.

\section{King Edward Hospital. Durban, S. Africa. \\ G. D. Campbell. \\ W. G. MCNEILL.}

REFERENCES

' Hugh-Jones, P., Lancet, 1955, $2,891$.

2 Gelfand, M., The Sick African, 1957. Juta and Co., Capetown.

\section{Boxing}

SIR,-Boxing in the only game in which you try to injure your opponent. Since the coup de grace is the "knockout" it is what every boxer aims at; no matter how much he has been out-pointed in previous rounds, he is the winner if he scores a knock-out. For once I would agree with Dr. Edith Summerskill about the dangers to the brain.

Another termination of a fight is when one boxer sustains a cut-brow, which by reason of the bleeding blinds him. He is the loser. What seems un-British is that his opponent is instructed to play to it. A stout, silkmattress suture inserted during the interval would meet the case. The cut could be stitched subcutaneously at the end of the fight.-I am, etc.,

London, S.W.16.
SIR,-I suggest that Dr. J. A. Waycott (Journal. June 20. p. 1591) reads the reply ${ }^{1}$ from the honorary medical officers of the Amateur Boxing Association to the leading article in the Lancet?. Of course there can be no "official policy" of the B.M.A. on boxing, or for that matter on ski-ing, Rugby and Association football, motor racing, mator-cycle racing, hunting, or horseriding, at which, on percentage, there is a greater number of fatalities and injuries.

No one is obliged to box and the medical control of boxers is as high as, if not higher than, that of any sport May I repeat the Prime Minister's statement in the House of Commons on the subject on June 18: "I am not persuaded that the appointment of a Select Committee would be appropriate ....1 think we should look to the bodies responsible for controlling the sport, both amateur and professional, to pay due regard to all these matters ".3-I am, etc.,

\section{J. L. BLonstein,}

London, W.1.

REFERENCES

1 Lancet, 1959, 1, 1280.

2 ibid, 1959, 1, 1185.

s Hansard, 1959, 607, No. 128, Col. 647.

London, S.E.18.

\section{Printing the "B.M.J."}

SIR,-I wish to protest most strongly against the publication of the B.M.J. by non-union labour during a dispute. At a time when you are supporting a doctors' wage claim it is unwise as well as immoral to take steps which mititate against successful action by a section of the public.

It is nonsense to suppose that any doctor requires the B.M.J. in any given week to carry on his day-to-day practice. As for the accusation of "sabotage of the N.H. S.", I find this hypocritical in one who recently advocated a walk-out from the N.H.S., and who looks with favour on schemes of the Fellowship for Freedom.I am, etc.,

\section{G. Richman.}

\section{B.C.G. Vaccination}

SIR,-It is disappointing to note that the combined American authors in their paper, “The Case against B.C.G." (Journal, Iune 6, p. 1423), take no cognizance of the fact that B.C.G. vaccination is at least a complete prevention against the two very common forms of childhood tuberculosis-tuberculous meningitis and miliary tuberculosis. It is also highly probable that it will prevent metastatic foci developing in the genitourinary system. This is of great importance in adolescent girls where a primary infection may well result in life-long sterility. A further factor that they do not stress is that in B.C.G. vaccination at least the site of election of the primary is extra thoracic. This will at least ensure that pulmonary endogenous breakdown, with spreading disease in the lungs, does not occur. It may be argued by many that this is of minor importance as the majority of re-infection tubercle is of exogenous nature, but so far this has never been satisfactorily proved.

I think that there are many doctors who would hardly agree with our American colleagues that naturally occurring tuberculous lesions are " benign."

We are all dependent on each other, and with the rapid increase in air travel the world is a very much smaller place than it was. It is quite unrealistic to pre- 